Doi: HTTPS://DOI.ORG/10.23910/2/2020.0331

\title{
Anti-Diabetic Properties of Bitter Gourd
}

\author{
Shweta Sharma* and Viveka Katoch
}

Dept. of Vegetable Science and Floriculture, CSKHPKV, Palampur, H.P. (176 062), India

\section{Corresponding Author}

Shweta Sharma

e-mail: shwetasharma15123@gmail.com

\section{Article History}

Article ID: IJEP0331

Received in 14 ${ }^{\text {th }}$ December, 2019

Received in revised form $27^{\text {th }}$ December, 2019

Accepted in final form $03^{\text {rd }}$ January, 2020

\section{Abstract}

Bitter gourd (Momordica charantia L.) is a fruit that traditionally believe to have benefits on health. It is a widely used traditional remedy for the treatment of diabetes. Bitter gourd is suggested for hyperglycemia treatment due to its ability to reduce glucose levels in the body. Some of the bioactive compounds present in it possess anti diabetic effects. It contains phytochemicals with anti-diabetic properties such as charantin, $p$-insulin and vicine. Hypoglycemic effects of bitter gourd have been shown in clinical studies. This review will focus on the hyperglycemic properties of bitter gourd.

Keywords: Antidiabetic, bitter gourd, phytochemicals

\section{Introduction}

Bitter gourd (Memordica charantia), an annual fruity vegetable, is a member of the Cucurbitaceae family and widely grown in Asia, South America, India, Caribbean, East Africa, Middle East and America (Sorifa, 2018). Bitter gourd is also referred to as bitter melon, karela or balsam pear (Satkar et al., 2013). It is one of nature's most bountiful gifts and is one of the discarded vegetables just because of its bitter taste. It is derived from the latin word Momordica means "to bite" referring to the jagged edges of the leaves, which appear as if they have been bitten (Anilakumar et al., 2015). In Ayurveda, the fruit is considered as tonic, stomachic, stimulates digestion, emetic, antibilious, laxative and alterative. Apart from this, it is a powerful nutrient-dense plant composed of a complex array of beneficial compounds. These include phytochemicals, vitamins, minerals and antioxidants, which all contribute to its remarkable versatility in treating a wide range of illnesses (Kumari et al., 2017). It has been used widely in folk medicine as a remedy for diabetes (Kumar et al., 2010). As per the estimates of the World Health Organization, around 422 million adults have a form of diabetes mellitus (WHO, 2016). Bitter gourd is a widely used traditional remedy for hyperglycemia. While the medicinal properties of this plant have been studied extensively using in vitro and animal models, the clinical efficacy and safety in humans is needed to be studied. Therefore, bitter gourd has the potential to become a component of the diet for diabetic patients. This review discusses the benefits of bitter gourd in the context of diabetes.

\section{Chemical Constituents}

Diabetes is a killer disease that affects humans of different ages and different phytochemicals are found to be related to anti-diabetic activity (Patel et al., 2006). The mixture of steroidal saponins known as charantins, insulin-like peptides and alkaloids are the hypoglycemic chemicals of Momordica charantia and are mainly concentrated in the fruits (Raman and Lau, 1996). Charantin is a mixture of two steroidal saponin compounds (1:1) sitosteryl glucoside $\left(\mathrm{C}_{35} \mathrm{H}_{60} \mathrm{O}_{6}\right)$ and stigmasteryl glucoside $\left(\mathrm{C}_{35} \mathrm{H}_{58} \mathrm{O}_{6}\right)$ known to have hypoglycemic activity, which can be isolated from Momordica charantia fruit (Paul and Raychaudhuri, 2010). It has been reported that charantin on taking either orally or intravenously in rabbits produces hypoglycemic effects (Lolitkar and Rao, 1966). Protein P-insulin is a polypeptide consists of 166 amino acids with a molecular weight of about 11,000 Dalton and is known to have hypoglycemic effects. Khanna and Mohan (1973) reported that besides the fruits, $\mathrm{p}$-insulin was also found in seeds and tissue cultures of Momordica charantia. Seeds of bitter gourd contain pyrimidine nucleoside vicine (Dutta et al., 1981 and Barron et al., 1982). Vicine has been found to induce hypoglycemia in rats, when administered intraperitoneally.

\subsection{Charantin}

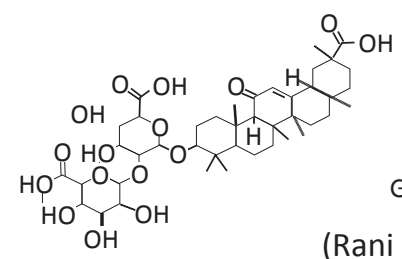
Glucose -

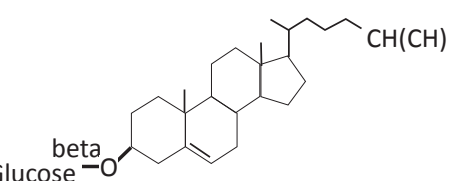

(Rani et al., 2014; Chanda et al., 2019) 
2.2. Vicine

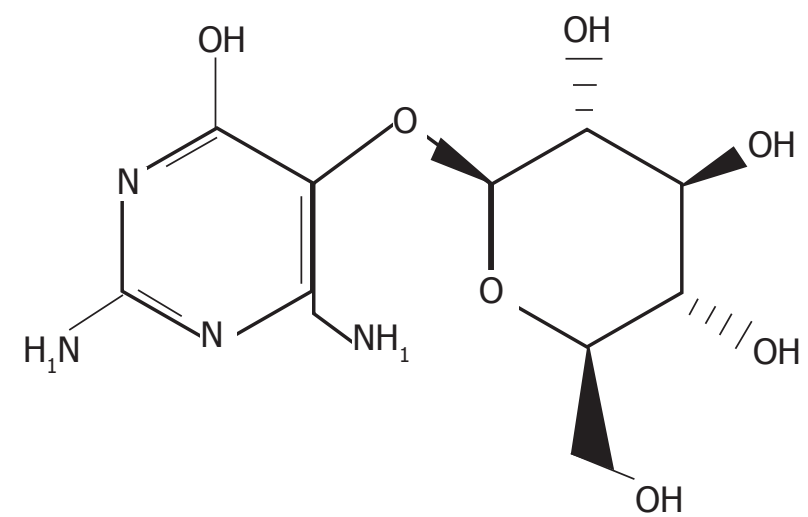

(Upadhyay et al., 2015)

Bitter gourd has tremendous beneficial effects in the treatment of diabetes. A number of studies were conducted to show that three basic components of bitter gourd alkaloids, steroidal and saponins, insulin-like compounds that provoked hypoglycemic potential benefits for diabetes patients. The effect of these chemical compounds becomes more efficient in fruit parts where they are present in abundance (Yeh et al., 2003). These hypoglycemic compounds either regulate insulin release directly or alter glucose metabolism and its insulin-like effect. These compounds improve blood sugar levels by increasing glucose uptake and glycogen synthesis in the liver, muscles and fat cells (Raman and Lau, 1996 and Harinantenaina et al., 2006). Bitter gourd contains another bioactive compound i.e. lectin that has insulin-like activity due to its linking together two insulin receptors. This lectin lowers blood glucose concentrations by acting on peripheral tissues and, similar to insulin's effects in the brain, suppressing appetite (Thakur and Sharma, 2016). Lectin is considered a major contributor to the hypoglycemic effect that develops after eating bitter gourd and it may be a way of managing adult-onset diabetes. Lectin binding is nonprotein specific, and this is likely why bitter gourd has been credited with immunostimulatory activity by linking receptors that modulate the immune system, thereby stimulating said receptors. The bioactive compounds present in fruit of bitter gourd activate a protein called AMPK (AMP-activated protein kinase $\alpha$ ), which is well known for regulating fuel metabolism and enabling glucose uptake processes which are impaired in patients with diabetes (Anilakumar et al., 2015).

\section{Clinical Studies}

The hypoglycemic effect of these chemicals is more pronounced in fruit, where they are present in higher abundance. These hypoglycemic compounds either regulate insulin release directly or alter glucose metabolism and its insulin-like effect (Upadhyay et al., 2015). Ahmed et al. (1998) reported that there was a significant increase in the number of cells in the pancreas of streptozotocin-induced diabetic rats after treatment with 8 weeks of bitter gourd fruit juice. Dietary fiber has been reported to increase short-chain fatty acids (SCFAs) production. This SCFA is able to decrease postprandial glucose levels by increasing blood free fatty acids. This free fatty acid can inhibit glucose metabolism through GLUT4 transporter activity inhibition (Kelley and Mandarino, 2000). A significant increase was found in the number of cells in pancreas of streptozotocin induced diabetic rats after 8 weeks of bitter gourd fruit juice treatment (Ahmed el al., 2001).

The beneficial hypoglycemic effects of fruit pulp, seed and whole plant extracts have also been documented in rat (Jayasooriya et al., 2000; Ojewole et al., 2005). Sureshkumar et al. (2003) studied the effect of bitter gourd on streptozotocininduced diabetic rats with particular emphasis on kidney heparin sulfate. It was observed that bitter gourd extracts remarkably lowered the blood sugar in diabetic rats (Virdi et al., 2003; Batran et al., 2006).

Bitter gourd fruit feeding decreased blood glucose levels on the hyperglycemia rats group due to the effect of glucose metabolism. Bitter gourd fruit suppressed the increase of blood glucose was presumably related to the existence of pectin and other dietary fiber (Rohajatien et al., 2018). Predominant soluble fiber in the bitter gourd is pectin. Pectin is able to form high viscosity in the digestive tract thus decreases postprandial blood glucose by inhibiting glucose absorption. Gel structure of pectin entraps nutrients absorption (Nugent, 2005).

Bitter gourd fruit aqueous extract has a significant role in alleviating kidney damage in the streptozotocin-induced diabetic rats (Abdollahi et al., 2011). Administration of alcohol of an extract of bitter gourd produced a dose-dependent decrease in blood glucose levels in Alloxan induced rabbits. There was a significant fall in blood sugar level in high dose (1.5 $\mathrm{gm} \mathrm{kg}^{-1}$ ) in comparison to low dose $\left(0.5 \mathrm{gm} \mathrm{kg}^{-1}\right)$ and median dose $\left(1 \mathrm{gm} \mathrm{kg}^{-1}\right.$ ) shown by LSD test. Recently, 8 new cucurbitane-type glycosides were isolated by bioactivityguided fractionation that also exhibited a hypoglycemic effect in vitro (Zhang et al., 2014). Khanna and Mohan (1973) reported the presence of $p$-insulin in seeds and tissue cultures of bitter gourd. Charantin-rich extract is a potential agent for increasing insulin-sensitivity in type 2 diabetic (T2D) patients (Wang et al., 2014). Similarly, in vivo clinical human research, oral digestion of bitter gourd plants shown low toxicity (Rathi et al., 2002).

\section{Conclusion}

A lot has been written about the beneficial aspects of bitter gourd in the treatment of diabetes as it is a host of bitter chemicals in which, which are hypoglycemic in action. Doctors all over the world are recommending bitter gourd juice early in the morning or to include it in the daily diet. Regular consumption of bitter gourd over a period of time helps to bring the blood sugar level down. The hypoglycemic effects of 
bitter gourd have been well documented in the clinical studies. Hence, bitter gourd is found to be extremely effective in the treatment of diabetes.

\section{References}

Abdollahi, M., Zuki, A.B., Rezaeizadeh, A., Goh, Y.M., Noordin, M.M., 2011. Effects of Momordica charantia aqueous extract on renal histopathological changes associated with streptozotocin-induced diabetes mellitus type II in neonatal rats. Journal of Medicinal Plants Research 5, 1779-1787.

Ahmed, I., Lakhani, M.S., Gillett, M., John, A., Raza, H., 2001. Hypotriglyceridemic and hypocholesterolemic effects of anti-diabetic Momordica charantia (karela) fruit extract in streptozotocin-induced diabetic rats. Diabetes Research and Clinical Practice 51, 155-161.

Ahmed., Adeghate, I,E., Sharma, A.K., Pallot, D.J., Singh, J., 1998. Effects of Momordica charantia fruit juice on islet morphology in the pancreas of the streptozotocindiabetic rat. Diabetes Research and Clinical Practice 40, 145-151.

Anilakumar, K.R., Kumar, G.P., Ilaiyaraja, N., 2015. Nutritional, pharmacological and medicinal properties of Momordica charantia. International Journal of Nutrition and Food Sciences 4, 75-83.

Barron, D., Kaouadji, M., Mariotte, A.M., 1982. Etude comparative de deux cucurbitacees a usage medicinal. Planta Medica 46, 184-186.

Batran, S.A.E.S., El-Gengaihi, S.E., El-Shabrawya, O.A., 2006. Some toxicological studies of Momordica charantia L. on albino rats in normal and alloxan diabetic rats. Journal of Ethnopharmacology 108, 236-242.

Chanda, R., Samadder, A., Banerjee, J., 2019. Anti-diabetic activity of Momordica charantia or bitter melon: a review. Acta Scientific Pharmaceutical Sciences 3, 24-30.

Dutta, P.K., Chakravarty, A.K., Chowdhury, U.S., Pakrashi, S.C., 1981. Vicine, a favism-inducing toxin from Momordica charantia Linn. Indian Journal of Chemistry 20B, 669-671.

Harinantenaina, L.M., Tanaka, S., Takaoka., Oda, M., Mogami, O., Uchida, M., Asakawa, Y., 2006. Momordica charantia constituents and antidiabetic screening of the isolated major compounds. Chemical and Pharmaceutical Bulletin 54, 1017-1021.

Jayasooriya, A.P., Sakono, M., Yukizaki, C., Kawano, M., Yamamoto, K., Fukuda, N., 2000. Effects of Momordica charantia powder on serum glucose levels and various lipid parameters in rats fed with cholesterol-free and cholesterol-enriched diets. Journal of Ethnopharmacology 72, 331-336.

Kelley, D.E., Mandarino, L.J., 2000. Fuel selection in human skeletal muscle in insulin resistance: a reexamination. Diabetes 49, 677-683.

Khanna, P., Mohan, S., 1973. Isolation and identification of diosgenin and sterols from fruits and in vitro cultures of Momordica charantia Linn. The Indian Journal of Experimental Biology 11, 58-60.

Kumar, D.S., Sharathnath, K.V., Yogeswaran, P., Harani, A., Sudhakar, K., Sudha, P., Banji, D., 2010. A medicinal potency of Momordica charantia. International Journal of Pharmaceutical Sciences Review and Research 1, 95-100.

Kumari, P., Verma, R.B., Nayik, G.A., Solankey, S.S., 2017. Antioxidant potential and health benefits of bitter gourd (Momordica charantia L.). Journal of Postharvest Technology 05, 1-8.

Lolitkar, M.M., Rao, M.R.R., 1966. Pharmacology of a hypoglycaemic principle isolated from the fruits of Momordica charantia. Linn. Indian Journal of Pharmacy 28, 129-133.

Nugent, A.P., 2005. Health properties of resistant starch. Nutrition Bulletin 30, 27-54.

Ojewole, J.A., Adewole, S.O., Olayiwola, G., 2005. Hypoglycaemic and hypotensive effects of Momordica charantia Linn (Cucurbitaceae) whole-plant aqueous extract in rats. Cardiovascular Journal of South Africa 17, 227-232.

Patel, P.M., Patel, K.N., Patel, N.M., Goyal, R.K., 2006. Development of HPTLC method for estimation of charantin in herbal formulations. Pharmacognosy Magazine 2, 224-226.

Paul, A., Raychaudhuri, S.S., 2010. Medicinal uses and molecular identification of two Momordica charantia varieties- a review. Electronic Journal of Biology 6, 43-51.

Raman, A., Lau, C., 1996. Anti-diabetic properties and phytochemistry of Momordica charantia L. (Cucurbitaceae). Phytomedicine 2, 349-362.

Rani, B., Jat, B.L., Pandey, M., Malhotra, J., Mohan, L., Bugasara, P.S., Maheshwari, R.K., 2014. Dietetic corollary ofMomordica charantia for vivaciousness and sanguinity. International Journal of Pharmaceutical Research and Bio-Science 3, 141-154.

Rathi, S.S., Grover, J.K., Vikrant, V., Biswas, N.R., 2002. Prevention of experimental diabetic cataract by Indian ayurvedic plant extracts. Phytotherapy Research 16, 774-777.

Rohajatien, U., Harijono., Estiasih, T.,Wahyuni, E.S., 2018. Bitter melon (Momordica charantia $\mathrm{L}$ ) fruit decreased blood glucose level and improved lipid profile of streptozotocin induced hyperglycemia rats. Current Research in Nutrition and Food Science 06, 359-370.

Satkar, K.P., Kulthe, A.A., Chalke, P.R., 2013. Preparation of bitter gourd ready to serve beverage and effect of storage temperature on its keeping quality. The Bioscan 8, 115-117.

Sorifa, A.M., 2018. Nutritional compositions, health promoting phytochemicals and value added products of bitter 
gourd: a review. International Food Research Journal 25, 1763-1772.

Sureshkumar, G., Shetty, A.K., Salimat, P.V., 2003. Modulatory effect of bitter gourd (Momordica charantia Linn.) on alterations in kidney heparin sulfate in streptozotocininduced diabetic rats. Journal of Ethnopharmacology 115, 276-283.

Thakur, M., Sharma, R.K., 2016. Bitter gourd: health properties and value addition at farm scale. Marumegh 1, 17-21.

Upadhyay, A., Agrahari, P., Singh, D.K., 2015. A review on salient pharmacological features of Momordica charantia. International Journal of Pharmacology 11, 405-413.

Virdi, J., Sivakami, S., Shahani, S., Suthar, A.C., Banavalikar, M.M., Biyani, M.K., 2003. Antihyperglycemic effects of three extracts from Momordica charantia. Journal of Ethnopharmacology 88, 107-111.
Wang, H., Kan, W., Cheng, T., Yu, S., Chang, L., Chuu, J., 2014. Differential anti-diabetic effects and mechanism of action of charantin-rich extract of Taiwanese Momordica charantia between type 1 and type 2 diabetic mice. Food and Chemical Toxicology 69, 347-356.

WHO (World Health Organization), 2016. World Health Day 2016: Beat Diabetes. World Health Organization. www. who.int/campaigns/world-health-day/2016/en/.

Yeh, G.Y., Eisenber, D.M., Kaptchuk, T.J., Phillips, R.S., 2003. Systematic review of herbs and dietary supplements for glycemic control in diabetes. Diabetes Care 26, 1277-1294.

Zhang, L., Liaw, C., Hsiao, P., Huang, H., Lin, M., Lin, Z., Hsu, F., Kuo, Y., 2014. Cucurbitane-type glycosides from the fruits of Momordica charantia and their hypoglycaemic and cytotoxic activities. Journal of Functional Foods 6, 564-574. 